\title{
A STUDY ON CORRELATION OF PAP SMEAR, COLPOSCOPY AND COLPOSCOPIC DIRECTED BIOPSY IN WOMEN WITH UNHEALTHY CERVIX
}

\author{
Sudha Rani Gandi1, Pallavi Satish Vishwekar ${ }^{2}$
}

${ }^{1}$ Associate Professor, Department of Obstetrics and Gynaecology, Dr. D. Y. Patil Medical College, Nerul, Navi Mumbai. ${ }^{2}$ Assistant Professor, Department of Obstetrics and Gynaecology, Dr. D. Y. Patil Medical College, Nerul, Navi Mumbai.

\section{ABSTRACT}

\section{BACKGROUND}

Cervical cancer develops from the premalignant lesions (CIN) over a period of time which can be diagnosed by screening tests. The Papanicolaou (Pap) smear was the initial screening test for CIN and invasive cervical cancer. However, the simultaneous use of Pap smear and colposcopy has been shown to increase the rate of the cervical cancer detection. So this study was done to assess the reliability of colposcopy by correlating the findings of colposcopy with cytology and colposcopic directed biopsy in women with unhealthy cervix and also to analyse various risk factors involved in CIN lesions of the cervix.

\section{MATERIALS AND METHODS}

This was a prospective observational study conducted in 100 women aged between 18 to 65 years with unhealthy cervix. All were subjected to screening by Pap smear, colposcopy and colposcopic guided biopsy and their results were compared and correlated. Final correlation of the Pap smear and colposcopy were based on histopathology results.

\section{RESULTS}

In the present study, the sensitivity of colposcopy was more than Pap smear (92.3\% Vs 69.25\%) but its specificity was only $60.9 \%$ compared to $83.9 \%$ of the Pap smear. This study demonstrated a high correlation between colposcopy and histology of $94.84 \%$. The correlation between Pap smear and colposcopy was $92.78 \%$. The correlation between Pap smear and histology was $84 \%$.

\section{CONCLUSION}

Colposcopy and colposcopic directed biopsy should be included along with Pap smear in screening for early detection of cancer of cervix since the accuracy of detection of cervical abnormalities is higher when they are used complementarily.

\section{KEYWORDS}

Cervical Cancer, Cervical Biopsy, Pap smear, Colposcopy, Unhealthy Cervix.

HOW TO CITE THIS ARTICLE: Gandi SR, Vishwekar PS. A study on correlation of Pap smear, colposcopy and colposcopic directed biopsy in women with unhealthy cervix. J. Evolution Med. Dent. Sci. 2017;6(7):515-518, DOI: 10.14260/Jemds/2017/109

\begin{abstract}
BACKGROUND
Cervical cancer is the fourth most common cancer affecting women and seventh overall world-wide after breast, colorectal and lung cancers.[1] It is also the fourth most common cause of cancer deaths in women worldwide. Almost $70 \%$ of the global burden falls in areas with lower levels of development and more than one fifth of all new cases are diagnosed in India. The cervical cancers were an estimated $5,28,000$ new cases \& 2,66,000 deaths from cervical cancer worldwide in 2012, accounting for $7.5 \%$ of all female cancer deaths.[1] Cervical cancer develops from the premalignant lesions of cervix over a variable period of time, which can be detected by screening tests. Cervical cancer can be prevented and almost cured when diagnosed in early stages. So early detection and treatment of these premalignant lesions is the principal object of cervical cancer prevention program. In many developed countries, health education, early detection and appropriate management achieve $80 \%$ reduction in
\end{abstract}

Financial or Other, Competing Interest: None.

Submission 01-01-2017, Peer Review 12-01-2017,

Acceptance 14-01-2017, Published 23-01-2017.

Corresponding Author:

Dr. Sudha Rani Gandi,

Associate Professor

Department of Obstetrics and Gynaecology,

Dr. D. Y. Patil Medical College,

Nerul, Navi Mumbai-400706.

E-mail: sudharani_gandi@yahoo.com

DOI: $10.14260 /$ jemds $/ 2017 / 109$ morbidity and mortality due to cervical cancer. These premalignant lesions can be detected with the help of screening tests which include Papanicolaou (pap) smear, colposcopy and histology. Pap smear is the initial simple, safe, non-invasive and effective screening test. In 1925 Hinselmann from Germany invented colposcopy for stereoscopic examination of the illuminated cervix and lower genital tract at a magnification of $\mathrm{x} 6$ to $\mathrm{x} 40$. It mainly demonstrates surface patterns and the terminal vascular network of the lesion. It is now routinely recommended for evaluation of women with abnormal Pap smear and for the diagnosis of suspicious invasive lesions in suspicious or unhealthy cervix. It identifies the appropriate sites for a biopsy and indicates the location of diseased tissue. The diagnosis of cervical neoplasia by colposcopy is based on recognition of four main features.

a. Intensity and colour tone of acetowhite areas.

b. Margins and surface contours of acetowhite area.

c. Vascular pattern.

d. Iodine staining.

Variation in quality and quantity of these atypical appearances help in differentiating CIN from other lesion or between types of CIN. In low-grade lesions, transparent to semi-transparent acetowhite areas with vague or feathery margins and fine punctation and/or mosaic seen. Opaque acetowhite areas with sharp margins and coarse punctation and/or mosaic are seen in high grade lesions. CIN lesions do 
not stain with iodine due to absence of glycogen. Colposcopic guided cervical biopsy can be taken from these abnormal areas. Combined with cytologic and histologic information colposcopy improves the accuracy of diagnosis of cervical cancer.

The aim of this study was to find the correlation of Pap smear, colposcopic findings and colposcopy guided cervical biopsy in the evaluation of women with unhealthy cervix and to analyse various risk factors involved in the CIN lesions of the cervix.

\section{MATERIALS AND METHODS}

This study is a prospective observational study conducted on women with unhealthy cervix who attended gynaecology outpatients department in Government General Hospital, Kakinada during July 2002 to May 2004. A total of 100 patients aged between 18-60 years with unhealthy cervix were subjected for screening. A complete case history of the patients is taken with reference to her marital status, age at first intercourse, menstrual history, number of conceptions, socioeconomic status, cigarette smoking, tobacco intake, history of exposure to sexually transmitted diseases, interval between children, history of abortion and usage of any contraception. The most common presenting complaints are leucorrhoea, foul smelling vaginal discharge, backache, postcoital bleeding and post-menopausal bleeding. Women with pregnancy and bleeding at the time of examination are excluded from the study. After complete general, systemic and gynaecological examination, patients were subjected to Pap smear for cytology, detailed colposcopic examination and colposcopic directed cervical biopsy. Cytology, colposcopy and histology results were compared. Pap smear was done using Ayer's spatula. It is smeared on the pre-labelled glass slides and fixed in 95\% ethyl alcohol. The interpretation of the Pap smear was made according to Bethesda system. Then colposcopic examination was done and findings were recorded using a computerised video colposcope. The following are the steps in colposcopic examination.

a. Inspection of unstained cervix after saline application.

b. Inspection through green filter.

c. Inspection of cervix after application of 3\%-5\% acetic acid for acetowhite areas, vascular design.

d. Inspection after application of Lugol's iodine, in which normal squamous epithelium which contains glycogen turns brown.

e. Inspection of the fornices and vaginal walls.

f. Colposcopic guided cervical biopsy.

Five Basic Characteristics Observed during Colposcopic Examination are

a. Vascular pattern.

b. Intercapillary distance.

c. Colour tone.

d. Surface contour.

e. Clarity of demarcation of lesion.

Colposcopic findings were categorised into 5 groupsNormal, Abnormal colposcopy, colposcopically suspect invasive carcinoma, unsatisfactory and miscellaneous. Colposcopic examination is classified as satisfactory if the squamocolumnar junction is seen in its entire circumference. Otherwise it is classified as unsatisfactory indicating that the endocervical border of the transformation zone is not clearly identified.

\section{Grade Findings on Colposcopy (Coppleson's Grading)}

Grade I- Flat transparent acetowhite epithelium, fine calibre and regular vessels with small intercapillary distance.

Grade II- Flat semi-transparent acetowhite epithelium; vessels with dilated calibre and regular shape, absence of atypical vessels and usually increased intercapillary distances.

Grade III- Opaque acetowhite epithelium, irregularly shaped and dilated vessels with variable intercapillary distance and irregular surface contour.

These colposcopic appearances are well correlated with histological diagnosis. In Grade I Colposcopic appearances, usual histological finding is a normal epithelium to minor dysplasia. Grade II colposcopic appearances correspond to moderate dysplasia to carcinoma in situ and Grade III is well correlated with carcinoma in situ to early invasive carcinoma. [2]

After defining abnormal area, colposcopy guided biopsy is done using cervical punch biopsy forceps from the acetowhite and iodine negative areas. The tissue is fixed in $10 \%$ formalin solution and sent for histopathological examination. Pap smear and colposcopic findings were correlated with histopathology obtained from colposcopic directed cervical biopsies and further management was decided.

\section{RESULTS}

- Out of the 100 patients, $80 \%$ of women are in the age group of $21-40$ years and $19 \%$ of women are in $41-60$ years. $42.5 \%$ of women aged $21-40$ years and $63.1 \%$ of women aged 41-60 years showed abnormal colposcopic findings. Most of the patients were multiparous (With parity 3 and above children) but the grand multipara showed $100 \%$ abnormal colposcopic findings.

- In relation to marital status and age at first intercourse analysis, it was found that more abnormal colposcopic findings were seen beyond 10 years of marital life and in women who were exposed to sexual activity below 15 years than in the group who started sexual activity after 21 years. Early the starting of marital life greater the incidence of abnormal colposcopic findings.

- $\quad 93 \%$ of women were from low socioeconomic status in which $46.23 \%$ had abnormal colposcopic findings. Commonest complaint was white discharge in $85 \%$ of whom $41.17 \%$ had abnormal colposcopic findings. $75 \%$ of the 8 patients with post-menopausal bleeding and $71.42 \%$ of the 7 patients with post-coital bleeding had abnormal colposcopic findings.

- On Pap smear, $76 \%$ of women had inflammatory cytology, $11 \%$ had CIN I, $7 \%$ had CIN II, III and 5\% showed Squamous cell carcinoma.

- Colposcopic findings suggest 54\% had normal findings, $31 \%$ had low grade lesion, $12 \%$ had high grade or suspicious of malignancy and $3 \%$ had unsatisfactory colposcopic examination.

- In Histopathology, $87 \%$ had chronic cervicitis, $4 \%$ had CIN I \& II, and $9 \%$ had squamous cell carcinoma.

- $\quad$ The colposcopic findings were compared with histologic results from colposcopic guided biopsy and Pap smear to assess the correlation between these three diagnostic methods. 
The following Tables Show the Correlations and Analysis

\begin{tabular}{|c|c|c|c|c|c|c|}
\hline \multirow{2}{*}{$\begin{array}{c}\text { Colposcopic } \\
\text { Grading }\end{array}$} & \multicolumn{5}{|c|}{ Pap smear Grading } \\
\cline { 2 - 7 } & 1 & 2 & 3 & 4 & 5 & Total \\
\hline Normal & 0 & 52 & 2 & 0 & 0 & $\mathbf{5 4}$ \\
\hline Grade I & 0 & 21 & 9 & 1 & 0 & $\mathbf{3 1}$ \\
\hline Grade II & 1 & 3 & 0 & 4 & 2 & $\mathbf{1 0}$ \\
\hline Grade III & 0 & 0 & 0 & 0 & 2 & $\mathbf{2}$ \\
\hline Unsatisfactory & 0 & 0 & 0 & 2 & 1 & $\mathbf{3}$ \\
\hline Total & $\mathbf{1}$ & $\mathbf{7 6}$ & $\mathbf{1 1}$ & $\mathbf{7}$ & $\mathbf{5}$ & $\mathbf{1 0 0}$ \\
\hline Table 1. Correlation of Colposcopic \\
Findings with Pap Smear Grading \\
\hline
\end{tabular}

The correlation between colposcopy and Pap smear was $92.78 \%$.

\begin{tabular}{|c|c|c|c|c|c|c|}
\hline $\begin{array}{c}\text { Colpo- } \\
\text { Scopic } \\
\text { Grading }\end{array}$ & \multicolumn{7}{|c|}{ Histology } \\
\cline { 2 - 7 } & Normal & $\begin{array}{c}\text { Chronic } \\
\text { Cervicitis }\end{array}$ & CIN I & CIN II & $\begin{array}{c}\text { Sq Cell } \\
\text { Carcinoma }\end{array}$ & Total \\
\hline Normal & 0 & 53 & 1 & 0 & 0 & $\mathbf{5 4}$ \\
\hline Grade I & 0 & 30 & 1 & 0 & 0 & $\mathbf{3 1}$ \\
\hline Grade II & 0 & 3 & 1 & 1 & 5 & 10 \\
\hline Grade III & 0 & 0 & 0 & 0 & 2 & $\mathbf{2}$ \\
\hline $\begin{array}{c}\text { Un- } \\
\text { satisfactory }\end{array}$ & 0 & 1 & 0 & 0 & 2 & 3 \\
\hline Total & 0 & $\mathbf{8 7}$ & $\mathbf{3}$ & $\mathbf{1}$ & $\mathbf{9}$ & $\mathbf{1 0 0}$ \\
\hline \multicolumn{7}{|c|}{$\begin{array}{c}\text { Table 2. Correlation of Colposcopic Findings } \\
\text { with Histology of Colposcopic Directed Biopsy }\end{array}$} \\
\hline
\end{tabular}
$94.84 \%$

The correlation between colposcopy and histology was

\begin{tabular}{|c|c|c|c|c|c|c|}
\hline \multirow{2}{*}{$\begin{array}{c}\text { Pap smear } \\
\text { Grading }\end{array}$} & \multicolumn{7}{|c|}{ Histology } \\
\cline { 2 - 7 } & Normal & $\begin{array}{c}\text { Chronic } \\
\text { Cervicitis }\end{array}$ & CIN I & CIN II & $\begin{array}{c}\text { Sq cell } \\
\text { Carcinoma }\end{array}$ & Total \\
\hline Grade 1 & 0 & 0 & 0 & 0 & 1 & $\mathbf{1}$ \\
\hline Grade 2 & 0 & 73 & 2 & 1 & 0 & $\mathbf{7 6}$ \\
\hline Grade 3 & 0 & 10 & 1 & 0 & 0 & $\mathbf{1 1}$ \\
\hline Grade 4 & 0 & 3 & 0 & 0 & 4 & $\mathbf{7}$ \\
\hline Grade 5 & 0 & 1 & 0 & 0 & 4 & $\mathbf{5}$ \\
\hline Total & $\mathbf{0}$ & $\mathbf{8 7}$ & $\mathbf{3}$ & $\mathbf{1}$ & $\mathbf{9}$ & $\mathbf{1 0 0}$ \\
\hline
\end{tabular}

Table 3. Correlation of Pap smear Grading with Histology

The correlation between Pap smear and histology was $84 \%$.

\begin{tabular}{|c|c|c|c|}
\hline \multirow{2}{*}{ Pap smear } & \multicolumn{3}{|c|}{ Histopathology } \\
\cline { 2 - 4 } & Positive & Negative & Total \\
\hline Positive & 9 (a) & $14(\mathrm{~b})$ & $\mathbf{2 3}$ \\
\hline Negative & $4(\mathrm{c})$ & $73(\mathrm{~d})$ & $\mathbf{7 7}$ \\
\hline Total & $\mathbf{1 3}$ & $\mathbf{8 7}$ & $\mathbf{1 0 0}$ \\
\hline \multicolumn{3}{|c|}{ Table 4. Analysis of Results of } \\
Pap smear and Histopathology \\
\hline
\end{tabular}

\begin{tabular}{|c|c|c|c|}
\hline \multirow{2}{*}{ Colposcopy } & \multicolumn{3}{|c|}{ Histopathology } \\
\cline { 2 - 4 } & Positive & Negative & Total \\
\hline Positive & $12(\mathrm{a})$ & $34(\mathrm{~b})$ & $\mathbf{4 6}$ \\
\hline Negative & $1(\mathrm{c})$ & $53(\mathrm{~d})$ & $\mathbf{5 4}$ \\
\hline Total & $\mathbf{1 3}$ & $\mathbf{8 7}$ & $\mathbf{1 0 0}$ \\
\hline \multicolumn{4}{|c|}{$\begin{array}{r}\text { Table 5. Analysis of Results of } \\
\text { Colposcopy and Histopathology }\end{array}$}
\end{tabular}

\begin{tabular}{|c|c|c|}
\hline Parameter & Pap smear & Colposcopy \\
\hline Sensitivity & $69.23 \%$ & $92.3 \%$ \\
\hline Specificity & $83.9 \%$ & $60.91 \%$ \\
\hline PPV & $39.13 \%$ & $26.08 \%$ \\
\hline NPV & $94.8 \%$ & $98.14 \%$ \\
\hline Accuracy & $82 \%$ & $65 \%$ \\
\hline \multicolumn{3}{|c|}{ Table 6 } \\
\hline
\end{tabular}

\section{DISCUSSION}

In the present study, maximum number of cases between 2140 years of age group showed highest incidence of abnormal colposcopic findings, this is in accordance with the view that dysplasias are premalignant lesions and they precede malignancies by one decade. Women who married early in their life and exposed to early sexual activity showed highest incidence of abnormal colposcopic findings. The incidence was almost nine times in those exposed to sexual activity before 15 years of age than in those exposed to sexual activity after 21 years of age which indicates early coitarche to be a risk factor for cervical cancer. Incidence of abnormal colposcopic findings are seen more in multiparous women and in women with postcoital and postmenopausal bleeding indicating that they are the significant risk factors for cervical cancer. The similar results were seen in the study done by Ashmita et al.[3]

The prevalence of CIN in the present study is $4 \%$ which is similar to the study by Ashmita et al[3] which showed a prevalence of $3.8 \%$.

In the present study, Colposcopy was found to be more sensitive (92.3\%) than Pap smear (69.23\%) whereas its specificity was only $60.9 \%$ compared to $83.9 \%$ of the Pap smear which is similar to the study by Ashmita et al ${ }^{[3]}$ which reported Pap smear had a better specificity $(83.33 \%$ Vs. 72.23\%) compared to colposcopy and colposcopy had a better sensitivity $(90.24 \%$ Vs. $19.5 \%)$ compared to Pap smear.

Another study by Joshi et al ${ }^{[4]}$ showed comparable results which reported sensitivity, specificity \& accuracy of the Pap smear to be $65.38 \%, 95.83 \%$ \& $80 \%$ respectively.

A study by Boicea et al[5] reported sensitivity of the colposcopy to be $83.6 \%$ and high correlation of colposcopy and histology as in the present study where the correlation between colposcopy and histology was $94.84 \%$.

In a study by Ramesh et al,[6] the sensitivity, specificity, positive predictive value \& negative predictive values of colposcopy were $83.33 \%, 46.42 \%, 40 \% \quad \& \quad 86.67 \%$ respectively which were comparable to the results in the present study.

In the study by Ouitrakul et al,[7] the accuracy of colposcopic directed biopsy in the diagnosis of cervical pathology was $87.8 \%$ with sensitivity, specificity, PPV and NPV of $84.9 \%, 100 \%, 100 \%$ \& $61 \%$ respectively which is comparable to the present study.

In another study by Krishna et al,[8] the colpohistological correlation and thus the predictive value of colposcopy is found to be $81.3 \%$ and cytohistological correlation was $58.8 \%$ which is comparable to the present study.

Hence, colposcopy and colposcopic directed biopsy of cervix should be included along with Pap smear in screening for early detection of cervical cancer since the accuracy of detection of cervical abnormalities is higher when these are used complementarily. 


\section{CONCLUSION}

Cervical cancer is one of the preventable and highly curable disease when diagnosed in early stages. Early diagnosis of CIN and invasive cervical cancer in the adult women is a desirable goal. CIN lesion and early invasive cancer are asymptomatic. So, it is important to develop an accurate screening tool to detect the disease in an early stage when it is amenable to treatment. In countries like India, Pap smear cytology, being a less expensive procedure, is used for screening of cervical cancer. Findings in this prospective study showed that colposcopy is definitely more sensitive than the Papanicolaou smear as a screening tool for CIN. But the Papanicolaou smear was, however, more specific as a screening tool for CIN than colposcopy. Colposcopy by magnifying 40 times helps in determining the appropriate site of cervical biopsy. Hence, the accuracy of detection of cervical abnormalities is higher when cytology, colposcopy and colposcopic directed cervical biopsy are used complementarily in the evaluation of women with unhealthy cervix.

\section{Abbreviations}

CIN-Cervical Intraepithelial Neoplasia, PPV-Positive Predictive Value, NPV-Negative Predictive Value.

\section{REFERENCES}

[1] International agency for research on cancer. Available from: http://globocan.iarc.fr. accessed on 30 Dec, 2016.
[2] Ananth R. Technique of colposcopy, Ascon medical instruments Pvt. Ltd, Madras, India 1999:1-28.

[3] Ashmita D, Shakuntala PN, Rao SR, et al. Comparison and correlation of PAP smear, colposcopy and histopathology in symptomatic women and suspicious looking cervix in a tertiary hospital care centre. Int J Health Sci Res 2013;3(5):50-9.

[4] Joshi C, Kujur P, Thakur N. Correlation of pap smear and colposcopy in relation to histopathological findings in detection of premalignant lesions of cervix in a tertiary care centre. Int J Sci Stud 2015;3(8):5560.

[5] Boicea A, PăTraşcu A, Şurlin V, et al. Correlations between colposcopy and histologic results from colposcopically directed biopsy in cervical precancerous lesions. Rom J Morphol Embryol 2012;53(3 Suppl):735-41.

[6] Ramesh G, Sudha R, Jayashree AK, et al. Colposcopic evaluation of unhealthy cervix. Journal of Clinical and Diagnostic Research 2012;6(6):1026-8.

[7] Ouitrakul S, Udomthavornsuk B, Chumworathayi B, et al. Accuracy of colposcopically directed biopsy in diagnosis of cervical pathology at Srinagarind hospital. Asian Pac J Cancer Prev 2011;12(9):2451-3.

[8] Algotar K, Nalawade A, Sachdev S. Predictive Value of Colposcopy in Cervical Cancer Screening. Bombay Hospital Journal 2004;46(3). 